\title{
Onde atuam, por que não atuam e o quão satisfeitos com o trabalho estão os licenciados em educação física?
}

\author{
¿Dónde actuan, por que no actuan y cuán satisfechos \\ con el trabajo están los licenciados en educación física?
}

\section{Where do they work, why do not work and how much satisfact about work are licensed in physical education?}

(iD) Gilson Junior Oliveira Lopes

Universidade Federal de Rondônia, Porto Velho, Rondônia, Brasil e-mail: gilsonjuniorpvh@gmail.com

(iD) Daniel Delani

Universidade Federal de Rondônia, Porto Velho, Rondônia, Brasil e-mail: danieldelani@unir.br

(iD) Silvia Teixeira de Pinho

Universidade Federal de Rondônia, Porto Velho, Rondônia, Brasil e-mail: silvia@unir.br

iD) Tatiane Gomes Teixeira Universidade Federal de Rondônia, Porto Velho, Rondônia, Brasil e-mail: tatiane.teixeira@unir.br

Resumo: O objetivo do presente estudo foi identificar locais de atuação, motivos de não atuação e satisfação profissional de licenciados em EDF egressos da Universidade Federal de Rondônia. Trata-se de uma pesquisa descritiva quantitativa que empregou questionário próprio e a Escala de Satisfação no Trabalho. Participaram 58 egressos. Os resultados evidenciaram que os locais de atuação mais citados foram escolas, academias e clubes. Os principais motivos para não atuação foram desvalorização profissional/salarial, falta de oportunidade e ter concurso público em outra área. Não foram encontradas diferenças quanto à satisfação no trabalho dos atuantes e não atuantes na EDF e tampouco entre os atuantes 
no ambiente escolar e não escolar. Conclui-se que a maioria dos sujeitos atuavam na EDF e estavam moderadamente satisfeitos no trabalho.

Palavras-chave: Educação Física. Atuação Profissional. Satisfação no Trabalho. Universidade.

Resumen: Objetivo: identificar lugares de actuación, motivos de no actuación y satisfacción profesional de licenciados en EDF egresados de la Universidad Federal de Rondônia. Método: investigación descriptiva cuantitativa que empleó cuestionario propio y la Escala de Satisfacción en el Trabajo. Participaron 58 graduados. Resultados: los lugares de actuación más citados fueron escuelas, academias y clubes. Los principales motivos para no actuación fueron devaluación profesional / salarial, falta de oportunidad y tener concurso público en otra área. No se encontraron diferencias cuanto la satisfacción en el trabajo de los actuantes y no actuantes en la EDF y tampoco entre los actuantes en el ambiente escolar y no escolar. Conclusión: la mayoría de los sujetos actuaban en EDF y estaban moderadamente satisfechos en el trabajo.

Palabras-clave: Educación Física. Actuación profesional. Satisfacción en el trabajo. Universidad.

Summary: Objective: to identify places of acting, reasons for not acting and professional satisfaction of graduates in physical education (EDF) of the Federal University of Rondonia. Methods: Descriptive quantitative research, obtained through self-structured questionnaire and Work Satisfaction Scale (Siqueira, 1995), whit sample of 58 graduates. Results: the most cited places of action were schools, gyms and clubs. The main reasons for not acting were professional/salary devaluation, lack of opportunity and public insolvency. No statistical differences were found between actuators and non-actuators in EDF or between professionals working in the school and non-school. Conclusion: the majority of subjects were working in their area of graduation and were moderately satisfied at work.

Keywords: Physical Education. Professional performance. Job Satisfaction. University.

Submetido em: 17-01-2019

Aceito em: 07-05-2019 
Onde atuam, por que não atuam e o quão satisfeitos com o trabalho...

Gilson Junior Oliveira Lopes • Daniel Delani • Silvia Teixeira de Pinho • Tatiane Gomes Teixeira

\section{Introdução}

O local de atuação do graduado em Educação Física (EDF) tem se expandido consideravelmente nas últimas décadas, caracterizando uma área com expressivas possibilidades de atuação, incluindo desde o tradicional campo escolar até hotéis, hospitais e unidades de saúde (CONFEF, 2002). Apesar da crescente expansão dos campos de atuação (CA) nessa área, bem como da regulamentação da profissão ocorrida há 20 anos, estudos tem indicado precarização da atuação no campo da Educação Física (MENDES; AZEVEDO, 2014; IORA et al., 2017).

Dentre os fatores frequentemente apontados para essa realidade, na literatura destacam-se a separação dos CA profissional (IORA et al.,2017), o cansaço decorrente do acúmulo de empregos (MENDES; AZEVEDO, 2014) e as jornadas de trabalho exaustivas (ESPIRITO SANTO; MOURÃO, 2006). Neste contexto, não é incomum encontrar graduados em EDF que não atuam em sua área de formação.

Também relacionado a esse contexto, a satisfação profissional na área de EDF merece atenção. Entendida como variável de natureza subjetiva que analisa como o sujeito avalia suas experiências no trabalho (AZEVEDO; MEDEIROS, 2012), ela é indicativa de motivação, qualidade de vida profissional e, consequentemente, de desempenho e aproveitamento efetivo da função pela sociedade. A importância da informação sobre o nível de satisfação no trabalho do profissional de EDF se dá na busca do conhecimento do atual contexto da profissão, pois se trata de uma área que vem sofrendo transformações históricas.

Diante da realidade apresentada, é fundamental conhecer os locais de atuação, bem como as condições de trabalho dos profissionais de EDF nas distintas regiões do Brasil. Somente dessa forma será possível compreender, satisfatoriamente, a realidade do mercado de trabalho nessa área e refletir acerca do futuro da profissão. Essa informação também é relevante para as institui- 
Onde atuam, por que não atuam e o quão satisfeitos com o trabalho...

Gilson Junior Oliveira Lopes • Daniel Delani • Silvia Teixeira de Pinho • Tatiane Gomes Teixeira

ções de ensino superior, a fim de fornecer informações para nortear a tomada de decisões em relação ao processo de formação profissional.

Nesse contexto, o presente estudo teve como objetivo investigar os locais de atuação, os motivos de não atuação e os níveis de satisfação profissional de egressos do curso de licenciatura em EDF da UNIR. Definiu-se essa população específica porque a instituição selecionada: a) é a única pública do Estado de Rondônia que oferece o curso de EDF; b) tem a proposta de licenciatura amplia$\mathrm{da}$, que inclui tanto disciplinas voltadas ao ambiente escolar como não escolar; e c) por conveniência e interesse direto dos pesquisadores envolvidos.

\section{Métodos}

O estudo caracteriza-se como descritivo observacional, de recorte transversal e abordagem quantitativa. A população foi composta por todos os alunos do Departamento de Educação Física da Universidade Federal de Rondônia (DEF/UNIR) que concluíram o curso de licenciatura em EDF entre 2008 e 2016 ( $n=151$ ). A amostra foi composta por 58 egressos definida por conveniência.

A coleta de dados foi realizada através de dois questionários: um semiestruturado elaborado pelos pesquisadores e a Escala de Satisfação no Trabalho (EST) de Siqueira (1995). Quatro (4) egressos responderam aos questionários via e-mail, 42 por meio do editor de formulários Google Docs; e 12 em versão impressa. As coletas foram realizadas em 2017. O questionário elaborado pelos pesquisadores continha perguntas abertas e fechadas, abordando questões referentes à: identificação e informações sociodemográficas (sessão 1), atuação profissional (sessão 2); e formação na área de EDF (sessão 4). Na presente pesquisa, foram analisadas e descritas somente as sessões 1 e 2 . Os demais dados serão apresentados em publicações futuras. 
Onde atuam, por que não atuam e o quão satisfeitos com o trabalho...

Gilson Junior Oliveira Lopes • Daniel Delani • Silvia Teixeira de Pinho • Tatiane Gomes Teixeira

A EST correspondeu à sessão 3 do instrumento. Foi previamente validada (Siqueira, 1995) e é composta por 25 itens. Nela, os profissionais avaliaram, em escala de 1 a 7 (de totalmente insatisfeito a totalmente satisfeito), o grau de satisfação no trabalho, considerando 5 dimensões: colegas, salário, chefia, natureza do trabalho e promoções.

A pesquisa faz parte do projeto “Formação e Atuação profissional na área de EDF", aprovado pelo Comitê de Ética em Pesquisa da Universidade Federal de Rondônia em 2017, sob número CAAE: 66590.617.0.0000.5300; e parecer 2.307.443. Atendeu as Resoluções 466/2012 e 510/2016 do Conselho Nacional de Saúde. Todos os participantes assinaram Termo de Consentimento Livre e Esclarecido.

Para análise dos dados foi empregada à estatística descritiva e inferencial. Para o teste de hipóteses dos dados não paramétricos, foi utilizado o teste de Kruskal Wallis. Para os dados paramétricos foi utilizada a análise de variância (ANOVA). Utilizou-se como valor de significância $p<0,05$.

\section{Resultados}

\section{Características da amostra}

No total, 58 voluntários participaram da pesquisa $(38,67 \%$ da população total de egressos vivos do curso de EDF da UNIR graduados no período de 2008-2016). O percentual de voluntários por sexos (fem. $n=31 ; 53,45 \%$ ) foi similar (masc. $n=27 ; 46,55 \%$ ).

A maior parte dos respondentes concluiu a graduação de 20122016 (75,86\%), ou seja, tinham entre 0,5 e 4,5 anos de formados. Sete sujeitos concluíram entre 2008-2011 e outros sete (12,07\%) não responderam essa pergunta. Os egressos pesquisados, em sua maioria, eram solteiros $(n=31 ; 53,45 \%)$ ou casados $(n=22$; $37,93 \%)$, seguidos pelos divorciados/separados ( $n=4 ; 6,90 \%)$. Um sujeito não declarou o estado civil. 
Onde atuam, por que não atuam e o quão satisfeitos com o trabalho...

Gilson Junior Oliveira Lopes • Daniel Delani • Silvia Teixeira de Pinho • Tatiane Gomes Teixeira

A maioria dos respondentes residia em Porto Velho $(n=49$; $84,48 \%$ ). Então, pode-se deduzir que os profissionais formados em EDF na UNIR estão exercendo suas atividades profissionais onde se graduaram, ampliando a mão de obra e beneficiando a população local.

\section{CA Profissional}

Dos 58 egressos, a maior parte estava atuando em sua área de formação ( $n=40 ; 68,97 \%)$. Desse total, trinta $(51,72 \%)$ trabalhavam exclusivamente na EDF (grupo SOEF), e 10 (17,24\%) trabalhavam na EDF e em mais uma área ou desempenham outra função não inerente à formação (grupo $\mathrm{EF}+\mathrm{X})$. Catorze $(24,14 \%)$ não trabalhavam na EDF (grupo NEF) e quatro $(6,90 \%)$ não estavam trabalhando (grupo NT).

Como a questão financeira frequentemente é apontada por estudantes e profissionais como limitação da atuação na área de EDF, foi investigado se haviam diferenças nessa variável quanto às diferentes situações laborais (Tabela 1). Não foram encontradas diferenças significativas na renda familiar e própria daqueles que trabalham e não trabalham na Educação Física.

\section{Tabela 1 - Renda dos egressos do DEF/UNIR, segundo grupos de atuação pro- fissional}

\begin{tabular}{|c|c|c|c|c|c|}
\hline Grupos & SOEF & NEF & $E F+X$ & NT & $\begin{array}{l}\text { Valor } \\
\text { de } p\end{array}$ \\
\hline $\begin{array}{l}\text { Renda familiar } \\
(\mathrm{em} R \$)(\mathrm{n}=41)\end{array}$ & $\begin{array}{c}5.108,17 \pm 2.518,44 \\
(1.000-12.000)\end{array}$ & $\begin{array}{c}5.866,67 \pm 2.303,62 \\
(3.000-10.000)\end{array}$ & $\begin{array}{c}5.575,00 \pm 1.749,08 \\
(3.500-8.000)\end{array}$ & $\begin{array}{c}3.100,00 \pm 1.682,26 \\
(1.800-5.000)\end{array}$ & 0,15 \\
\hline $\begin{array}{l}\text { Renda própria } \\
(e m R \$)(n=27)\end{array}$ & $\begin{array}{c}2.983,69 \pm 1.303,73 \\
\left(1.000-6.000^{*}\right)\end{array}$ & $\begin{array}{c}3.492,86 \pm 1.758,42 \\
(1.700-7.000)\end{array}$ & $\begin{array}{c}2.537,50 \pm 873,31 \\
(1.500-3.500)\end{array}$ & 0 & 0,53 \\
\hline
\end{tabular}

SOEF: Trabalham somente na Educação Física; EF+X: Trabalham na Educação Física e também em outra área; NEF: Não trabalham na área de Educação Física; NT: Não trabalham. *Os dois que trabalham só na EDF e tem a maior renda ( $R \$ 6.000$ ambos) trabalham ambos em academias como instrutores e treinadores personalizados.

Fonte: elaborada pelos autores. 
Onde atuam, por que não atuam e o quão satisfeitos com o trabalho...

Gilson Junior Oliveira Lopes • Daniel Delani • Silvia Teixeira de Pinho • Tatiane Gomes Teixeira

Do total de 40 (68,97\% de 58) profissionais que trabalhavam na EDF, 32 ( $80 \%$ de 40 ) trabalhavam em apenas um campo da área de EDF; sete (17,5\% de 40 ) trabalhavam em dois CA dentro da EDF; e um $(2,5 \%)$ trabalhava em três campos. Na Tabela 2 , constam os CA dos sujeitos.

Tabela 2 - Locais de atuação dos egressos na área de EDF

\begin{tabular}{|c|c|c|c|}
\hline Variáveis & $\begin{array}{c}\text { SOEF } \\
n=30(\%)\end{array}$ & $\begin{array}{c}E F+X^{*} \\
n=10(\%)\end{array}$ & $\begin{array}{c}\text { Todos } \\
\mathrm{n}=40(\%)\end{array}$ \\
\hline Somente escola & $12(40)$ & $5(50)$ & $17(42,5)$ \\
\hline Somente academia & $8(26,67)$ & $3(30)$ & $12(30)$ \\
\hline Somente Pilates & $1(3,33)$ & $1(10)$ & $2(5)$ \\
\hline Somente Artes marciais & 0 & $1(10)$ & $1(2,5)$ \\
\hline Somente clube esportivo & $1(3,33)$ & 0 & $1(2,5)$ \\
\hline Escola e academia & $4(13,33)$ & 0 & $4(10)$ \\
\hline Academia e clube & $2(6,67)$ & 0 & $2(5)$ \\
\hline Academia e condomínio & $1(3,33)$ & 0 & $1(2,5)$ \\
\hline Escola, clube e condomínio & $1(3,33)$ & 0 & $1(2,5)$ \\
\hline
\end{tabular}

*CA considerando somente a área de EDF.

Fonte: elaborada pelos autores.

Em relação aos locais de intervenção, a escola teve o maior número de atuação exclusiva. A fim de compreender melhor os padrões de renda segundo CA, foi realizada comparação entre os sujeitos que atuam a) somente na escola, b) somente no ambiente não escolar; e c) nos ambientes escolar e não escolar (Tabela 3). 
Onde atuam, por que não atuam e o quão satisfeitos com o trabalho...

Gilson Junior Oliveira Lopes • Daniel Delani • Silvia Teixeira de Pinho • Tatiane Gomes Teixeira

Tabela 3 - Renda dos egressos DEF/UNIR que trabalham na área de EDF, segundo CA

\begin{tabular}{|c|c|c|}
\hline $\begin{array}{c}\text { CA na EDF } \\
\text { do grupo SOEF }\end{array}$ & $\begin{array}{l}\text { Renda familiar } \\
\text { (Média em R\$) }\end{array}$ & $\begin{array}{l}\text { Renda própria } \\
\text { (Média em R\$) }\end{array}$ \\
\hline $\begin{array}{l}\text { Somente na área escolar } \\
\qquad(\mathrm{n}=12)\end{array}$ & $\begin{array}{c}4.280,00 \pm 1.597,08 \\
(1.000-6.500) \\
(n=10)\end{array}$ & $\begin{array}{c}2.641,67 \pm 1081,86 \\
(1.000-3.800) \\
(n=6)\end{array}$ \\
\hline $\begin{array}{l}\text { Somente na área não escolar } \\
\qquad(\mathrm{n}=13)\end{array}$ & $\begin{array}{c}6.449,60 \pm 3.104,06 \\
(2.500-12.000) \\
(n=10)\end{array}$ & $\begin{array}{c}3.504,44 \pm 1.541,00 \\
(2.000-6.000) \\
(n=9)\end{array}$ \\
\hline $\begin{array}{c}\text { Área escolar e } \\
\text { não escolar (n=5) }\end{array}$ & $\begin{array}{c}3.825,00 \pm 1.260,62 \\
(2.500-5.000) \\
(n=4)\end{array}$ & $\begin{array}{c}2.325,00 \pm 537,74 \\
(1.800-3.000) \\
(n=5)\end{array}$ \\
\hline
\end{tabular}

Fonte: elaborada pelos autores.

Na Tabela 3, verifica-se que a renda própria média dos grupos é similar, sem diferenças estatísticas. É relevante esclarecer que alguns sujeitos não responderam à questão sobre renda, razão pela qual os números de sujeitos descritos na Tabela 3 são inferiores quando considerados a divisão dos grupos segundo atuação ou não na área de EDF.

A pesquisa revelou que $14(24,14 \%)$ egressos do curso de EDF não trabalhavam na área de EDF. Na Tabela 4, constam os campos de atuações deles. A maioria $(n=10)$ dos egressos dos grupos NEF e NT já trabalharam na área de EDF após a graduação, 5 nunca trabalharam em EDF e 3 não responderam à questão. 
Onde atuam, por que não atuam e o quão satisfeitos com o trabalho...

Gilson Junior Oliveira Lopes • Daniel Delani • Silvia Teixeira de Pinho • Tatiane Gomes Teixeira

Tabela 4 - CA de egressos EDF/UNIR não atuantes na área

CA

Frequência $(n=14) \quad$ Percentual (\%)

\begin{tabular}{l|l|l}
\hline Segurança Pública & 4 & 28,57 \\
\hline Funcionário Público como professor ou administrativo & 3 & 21,43 \\
\hline Direito & 2 & 14,29 \\
\hline Funcionário Público na área de limpeza & 1 & 7,14 \\
\hline Construção civil & 1 & 7,14 \\
\hline Estética & 1 & 7,14 \\
\hline Shopping (supervisão de equipes) & 1 & 7,14 \\
\hline Cuidador de idosos & 1 & 7,14 \\
\hline
\end{tabular}

Fonte: elaborada pelos autores.

Além de identificar os egressos que não exerciam suas atividades profissionais na sua área de graduação, verificamos os motivos apontados para não atuação na área de EDF. Foram eles: 1) desvalorização ou insatisfação salarial/profissional ( $n=6 ; 33,33 \%) ; 2$ ) falta de oportunidade ( $n=3 ; 16,67 \%)$; 3 ) ter concurso público em outra área $(n=3 ; 16,67 \% ; 4)$ não ter interesse $(n=2 ; 11,11 \%)$; 5$)$ seguridade trabalhista ( $n=1 ; 5,56 \%)$; e 6) não concordância com o modelo educacional atual ( $n=1 ; 5,56 \%)$. Quatro sujeitos não responderam à questão ou a responderam de forma não compreensível.

\section{Satisfação no Trabalho}

No presente estudo, utilizamos a EST (Siqueira, 1995) para investigar de forma objetiva se a satisfação profissional dos egressos do DEF/UNIR difere em função do campo de atuação. Foram realizadas análises tanto quanto à atuação ou não na EDF (Tabela 5) quanto dos distintos ambientes de atuação na EDF (Tabela 6). 
Onde atuam, por que não atuam e o quão satisfeitos com o trabalho...

Gilson Junior Oliveira Lopes • Daniel Delani • Silvia Teixeira de Pinho • Tatiane Gomes Teixeira

Tabela 5 - Mediana (menor-maior valor) da satisfação no trabalho dos graduados DEF/UNIR de 2008-2016, segundo ambientes de atuação profissional

\begin{tabular}{c|c|c|c|c|}
\hline \multirow{2}{*}{ Variáveis da EST } & $\begin{array}{c}\text { SOEF } \\
(n=34) *\end{array}$ & $\begin{array}{c}\text { EF+X** } \\
(n=10)\end{array}$ & $\begin{array}{c}\text { NEF*** } \\
(n=20)\end{array}$ & Todos $(n=64)$ \\
\hline Total & $4,68(1,16-6,48)$ & $4,84(3,12-6,48)$ & $4,48(1-5,34)$ & $4,62(1-6,48)$ \\
\hline Colegas & $5(1-7)$ & $5,1(4-6,6)$ & $4,8(1-6,6)$ & $5(1-7)$ \\
\hline Salário & $4,1(1-6,6)$ & $4,9(1,8-6)$ & $4,2(1-7)$ & $4,3(1-7)$ \\
\hline Chefia & $5(1,2-6,8)$ & $4,8(2,8-6,2)$ & $5(1-6,6)$ & $5(1-6,8)$ \\
\hline Natureza do trabalho & $4,8(1-7)$ & $5,1(3-6)$ & $4,6(1-5,4)$ & $4,8(1-7)$ \\
\hline Promoções & $4,2(1-5,6)$ & $4,3(2,6-6,4)$ & $4,2(1-6,2)$ & $4,2(1-6,4)$ \\
\hline
\end{tabular}

*Incluídas no SOEF 4 pessoas que preencheram EST de dois locais distintos na EDF; **/ncluídas somente EST da atuação na área de EDF; ***/ncluídos resultados de EST da atuação fora da EDF. SOEF: Trabalham somente na Educação Física; $\mathbf{E F + X + : ~ T r a b a l h a m ~ n a ~ E d u c a c ̧ a ̃ o ~ F i ́ s i c a ~ e ~ t a m b e ́ m ~ e m ~ o u t r a ~ a ́ r e a ; ~}$ NEF: Não trabalham na área de Educação Física.

Fonte: elaborada pelos autores.

A satisfação no trabalho foi similar entre os grupos, sem diferenças estatísticas. Referente ao nível de satisfação geral, não foram encontradas diferenças estatísticas entre os grupos escola (mediana 4,64), academias/clubes (mediana 4,72) e grupo que não atua na área da $\operatorname{EDF}(4,48)$, (todos: $p>0,20)$, a partir do teste de Kruskal-Wallis. Em média, o nível de satisfação indica indiferença em todos os CA. Observa-se que os egressos que desempenham suas funções na área escolar, do total de cinco, estão satisfeitos em três dimensões: colegas, chefia e natureza do trabalho. Já aqueles que atuam em academias ou clubes estão satisfeitos somente em uma dimensão: colegas. 
Onde atuam, por que não atuam e o quão satisfeitos com o trabalho...

Gilson Junior Oliveira Lopes • Daniel Delani • Silvia Teixeira de Pinho • Tatiane Gomes Teixeira

\section{Tabela 6 - Mediana e classificação dos escores de satisfação no trabalho de graduados DEF/UNIR de 2008-2016, segundo CA}

\begin{tabular}{c|c|c|c}
\hline \multirow{2}{*}{ Variáveis da EST } & $\begin{array}{c}\text { Escola } \\
(\mathrm{n}=22)^{*}\end{array}$ & $\begin{array}{c}\text { Academias ou Clubes* } \\
(\mathrm{n}=13)\end{array}$ & $\begin{array}{c}\text { NEF } \\
(\mathrm{n}=20)\end{array}$ \\
\cline { 2 - 4 } Total & $4,64(2,24-6,48)$ & $4,72(1,16-6,44)$ & $4,48(1-5,36)$ \\
& Indiferente & Indiferente & Indiferente \\
\hline \multirow{2}{*}{ Colegas } & $5,2(2-6,8)$ & $5(1-7)$ & $4,8(1-6,6)$ \\
& Satisfeito & Satisfeito & Indiferente \\
\hline \multirow{2}{*}{ Salário } & $4,4(1-6,4)$ & $3,6(1,4-6,6)$ & $4,2(1-7)$ \\
& Indiferente & Insatisfeito & Indiferente \\
\hline \multirow{2}{*}{ Chefia } & $5(1,8-6,8)$ & $4,6(1,2-6,6)$ & $5(1-6,6)$ \\
& Satisfação & Indiferente & Satisfação \\
\hline \multirow{2}{*}{ Natureza do trabalho } & $5(2-7)$ & $4,5(1-7)$ & $4,6(1-5,4)$ \\
& Satisfação & Indiferente & Indiferente \\
\hline \multirow{2}{*}{ Promoções } & $4,2(2,6-5,6)$ & $4(1,2-5)$ & $4,2(1-6,2)$ \\
& Indiferente & Indiferente & Indiferente \\
\hline
\end{tabular}

*Incluídas a EST de pessoas que trabalham em dois locais e responderam EST separado. NTEDF: Não trabalha em Educação Física.

Fonte: elaborada pelos autores.

\section{Discussão}

Em estudo realizado com egressos de EDF da Universidade de Cruz Alta (Rio Grande do Sul/RS), Panda e Santos (2013) também constataram que a maioria dos sujeitos estava atuando na área de sua formação. Esses resultados indicam que o mercado de trabalho brasileiro na área de EDF continua absorvendo os egressos. Por outro lado, os resultados diferenciam-se quando observados os percentuais de profissionais com atuação exclusiva na EDF. No estudo atual, o percentual de egressos atuantes exclusivamente em EDF $(51,72 \%)$ foi maior do que aqueles que atuavam em EDF e outra área ou outra função $(17,24 \%)$, e os que trabalham em outra área (24,14\%). Já no RS, o percentual de profissionais com atuação 
Onde atuam, por que não atuam e o quão satisfeitos com o trabalho...

Gilson Junior Oliveira Lopes • Daniel Delani • Silvia Teixeira de Pinho • Tatiane Gomes Teixeira

exclusiva em EDF era menor (23,52\%) do que aqueles que atuavam em EDF parcialmente (47,05\%), e aqueles que não trabalhavam na área (29,41\%). No mesmo sentido, Mendes e Azevêdo (2014), em Brasília, constataram que correspondia à minoria os profissionais de EDF atuantes em academias que tinham somente um emprego. Em relação à satisfação profissional, os egressos atuantes na área de EDF apresentaram níveis similares quando comparado com aqueles que não atuavam na área.

Diante dessas comparações, o mercado de trabalho em EDF de Porto Velho parece se apresentar menos concorrido que em outras regiões brasileiras, permitindo que o profissional não necessite ou não queira trabalhar em mais de um local. Corroborando esse entendimento, também observamos diferenças importantes entre a realidade encontrada no presente estudo e aquela identificada no RS, no que diz respeito aos motivos para não atuação na área de EDF. No RS, a falta de emprego foi o principal, com 70,58\% (PANDA; SANTOS, 2013), enquanto no presente estudo essa foi relatada por $16,67 \%$ dos sujeitos (falta de oportunidade). Nesse sentido, cultura, formação, desenvolvimento estatal, mercado de trabalho, situação econômica do estado, entre outros fatores provavelmente divergem e influenciaram os resultados. Outra possibilidade de análise é que a remuneração do profissional de EDF nessa cidade seja maior, ou mesmo que o custo de vida nela seja menor. Essas hipóteses estão fora do escopo do presente estudo e merecem investigações mais aprofundadas.

Além da oportunidade de atuar na área de EDF, no presente estudo, outras justificativas para não atuação foram desvalorização profissional/salarial e ser concursado em outra área. Entendemos que as duas justificativas estão relacionadas, visto que a maioria dos egressos não atuantes na EDF $(57,13 \%)$ eram funcionários públicos. Esse resultado pode se justificar pela estabilidade profissional dos cargos públicos. Através dela, o trabalhador se sente seguro e estável, ao inverso do trabalhador de iniciativa privada, pois para este não há garantia de permanência no emprego. 
Onde atuam, por que não atuam e o quão satisfeitos com o trabalho...

Gilson Junior Oliveira Lopes • Daniel Delani • Silvia Teixeira de Pinho • Tatiane Gomes Teixeira

Na visão de Azevedo e Medeiros (2012), a importância da satisfação no trabalho para a área do comportamento organizacional tem valor especial no setor público, visto que nesse setor de atuação alguns fatores como estabilidade, mudanças em decorrências de ciclos eleitorais etc. interferem nos ambientes de trabalho e, consequentemente, na satisfação dos seus servidores. Sobre essa temática, Rosa (2016) relata que o vínculo empregatício pode influenciar na satisfação do profissional. A autora realizou estudo de caso sobre fatores relacionados à satisfação no trabalho dos servidores da Secretaria de Estado da Fazenda do Governo de Santa Catarina. Constatou que servidores de vínculo efetivo tiveram maior média (6,28 num máximo de 7 pontos). Assim, pode-se justificar que a segurança no trabalho conquistada através do concurso público fora da EDF é um dos fatores determinantes para a não atuação na sua área de graduação.

O destaque na atuação dos egressos como funcionários públicos da área de segurança pública $(n=4)$ pode ser justificado, além da estabilidade, pelo baixo salário praticado na área de EDF, no Estado de Rondônia, em comparação com a área de segurança. Dados disponíveis no portal de Transparência do Governo de Rondônia (2017) revelam que enquanto um professor de EDF tem remuneração inicial de cerca de $R \$ 2.262,62$, a do policial civil é em torno de $R \$ 5.214,00$; e do policial militar $R \$ 3.532,04$. Além da estabilidade e remuneração, outro fator há de se levar em consideração: as profissões de policial civil e militar não necessitam de titulação em nível superior. Esse fato reforça o recorrente discurso da desvalorização do profissional de educação.

Com o propósito de aprofundar a discussão sobre a dimensão salarial, comparamos a renda mensal dos egressos atuantes e não atuantes na área de graduação. A renda não foi estatisticamente diferente quando comparados os profissionais que atuavam somente na EDF (SOEF), aqueles que atuavam na EDF e outra ( $E F+X)$ e aqueles que não atuavam na EDF (NEF). Com esse resultado, torna-se inviável afirmar que egressos que trabalham na EDF tem renda própria maior ou menor que aqueles que atuam em outras 
Onde atuam, por que não atuam e o quão satisfeitos com o trabalho...

Gilson Junior Oliveira Lopes • Daniel Delani • Silvia Teixeira de Pinho • Tatiane Gomes Teixeira

áreas. Assim, a justificativa por vezes apresentada para não trabalhar na área de EDF devido a baixos salários é questionável se considerarmos que, além da média, tanto os menores quanto os maiores salários não se diferenciam significativamente entre os grupos SOEF e NEF. Entende-se, dessa forma, que o salário não é o único a ser levado em consideração para não atuação na área de EDF.

Entretanto, ressalta-se a diferença de $\mathrm{R} \$ 2.200,00$ entre 0 maior salário relatado pelo grupo que atua na área não escolar $(R \$ 6.000,00)$ em comparação à maior renda registrada para quem atua exclusivamente na área escolar ( $(\$ 3.800,00)$. O grupo escolar apresentou-se indiferente nas dimensões salário e promoções, o que possivelmente se deve, pelo menos em parte, à característica do contrato trabalhista, através do qual as oportunidades de promoções e aumento salarial não dependem exclusivamente do seu desempenho.

A desvalorização social na área de EDF é outro fator que pode interferir na decisão do graduado em atuar nela ou não. Além de ser fonte de sustento, o trabalho também representa para o ser humano uma dimensão da vida responsável por gerar sentimentos de utilidade, pertencimento e realização pessoal. Dessa maneira, mesmo que o salário em outras áreas possa ser similar, se o indivíduo não se sente valorizado pelas pessoas que com ele atuam e/ou recebem os seus serviços, é compreensível que o sujeito busque sua fonte de sustento em funções menos desgastantes nas quais ele se sinta valorizado.

Relacionado, ao mesmo tempo, a questão salarial com a desvalorização profissional, merece atenção, especialmente no contexto das academias de ginástica/musculação, a forma como os estagiários têm sido utilizados como mão de obra barata. Na visão de Oliveira (2011), com a qual concordamos, esses estagiários acabam disputando vaga diretamente no mercado com os profissionais habilitados. O autor define academia como uma máquina de estágio, pois as empresas se favorecem pelo fato de os estagiários serem mais econômicos quanto aos encargos trabalhistas 
Onde atuam, por que não atuam e o quão satisfeitos com o trabalho...

Gilson Junior Oliveira Lopes • Daniel Delani • Silvia Teixeira de Pinho • Tatiane Gomes Teixeira

em comparação aos profissionais formados. Assim, Oliveira (2011, p. 5) aponta que a EDF contemporânea é a única profissão regulamentada que possui quatro tipos de 'profissionais' dividindo as vagas no campo de atuação: os estagiários, os provisionados, os ex-atletas, e, por fim, os profissionais graduados.

Além das quatro categorias de 'profissionais' indicadas por Oliveira (2011), Iora, Souza e Prietto (2017) apontam a divisão da área de EDF em licenciatura e bacharelado como uma das causas da desvalorização do profissional de Educação Física. Os trabaIhadores precisam se adaptar às necessidades que o mercado de trabalho exige, o que os leva muitas vezes ao trabalho informal, precário e com poucos direitos. Para Folle et al. (2008), a insatisfação no trabalho dos profissionais de EDF tem origens em fatores externos, como as condições de trabalho, situação econômica da classe, políticas públicas e o reconhecimento social dos educadores e da própria educação.

Nessa linha de pensamento, considerando que a atuação em EDF encontra-se atualmente dividida em dois campos principais, escolar e não escolar, realizamos comparações entre os sujeitos que atuavam somente em escolas e aqueles que atuavam somente na área não escolar, nas variáveis satisfação profissional e renda. Os egressos atuantes em EDF que tinham como local de atuação academia ou clubes estavam satisfeitos com os colegas de trabalho e insatisfeitos com o salário.

Essa insatisfação em relação ao salário já foi demonstrada previamente por Cordeiro (2009) entre profissionais atuantes em academias. Na presente pesquisa, embora não tenham sido encontradas diferenças entre os grupos, tanto a mediana quanto os menores e maiores salários relatados eram diferentes em cerca de $\mathrm{R} \$ 1.000$ entre os dois grupos (Tabela 3); os valores mais altos foram relatados por profissionais atuantes em ambiente não escolar. Por outro lado, o grupo não escolar estava insatisfeito e o escolar indiferente quanto ao salário, ou seja, mesmo com maior renda, os profissionais atuantes em ambientes não escolares se 
Onde atuam, por que não atuam e o quão satisfeitos com o trabalho...

Gilson Junior Oliveira Lopes • Daniel Delani • Silvia Teixeira de Pinho • Tatiane Gomes Teixeira

mostraram menos satisfeitos que os profissionais que atuam nas escolas.

Diante do exposto, aponta-se que a percepção de satisfação/ insatisfação salarial na área de EDF não depende somente do valor recebido. Variáveis que podem interferir nesse resultado são as já discutidas estabilidade profissional e as expectativas iniciais de remuneração dos profissionais. O profissional que atua na escola já conhece desde o momento do concurso o valor de sua remuneração. Já o profissional que atua fora da escola pode apresentar expectativas elevadas quanto ao salário e, na prática, não se concretizar, gerando frustração e insatisfação.

Ressalta-se ainda que, embora o profissional que atua em academias tem a possibilidade de incrementar sua renda através de serviços individualizados, ou seja, personal trainer, pode ocorrer alta demanda de trabalho e também variação na renda mensal do trabalhador. Para Gaspar (2013), o baixo salário encontrado na maioria dos CA da EDF leva os trabalhadores a procurarem diversos locais diferentes para vender sua força de trabalho e isso se reflete na carga horária de trabalho elevada.

Os resultados não apontaram diferença estatística na satisfação geral no trabalho dos profissionais de EDF dos grupos escola e academias/clubes, em consonância com estudo anteriormente já realizado com profissionais da mesma cidade (CORDEIRO, 2009). Apesar disso, durante a realização da pesquisa, alguns profissionais da área escolar, de maneira informal, mostraram insatisfação no trabalho, apontando como justificativa o estresse e variáveis da EST, como: insatisfação com salário e condições de trabalho. Por outro lado, é importante considerar também a possibilidade de os profissionais atuantes na academia terem receio de relatar insatisfação de forma direta, por não terem a estabilidade no emprego que o professor atuante em escolas públicas têm.

Diante do exposto, assim como este estudo, trabalhos de Folle et al. (2008) e Cordeiro (2009) concluíram que o local de atuação do profissional de EDF não é um fator consideravelmente influencia- 
Onde atuam, por que não atuam e o quão satisfeitos com o trabalho...

Gilson Junior Oliveira Lopes • Daniel Delani • Silvia Teixeira de Pinho • Tatiane Gomes Teixeira

dor do nível de satisfação do profissional da área de EDF. O mesmo pode ser dito sobre as variáveis de comparação sexo, formação acadêmica e o vínculo empregatício dos profissionais (FOLLE et al., 2008). Provavelmente, esse resultado se deve ao fato de que as análises consideram os grupos formados por várias pessoas. Isso significa que tanto na escola quanto fora dela há profissionais de EDF com alto grau de satisfação e com alto grau de insatisfação. Assim, a satisfação profissional parece ter componente individual subjetivo mais forte que os aspectos extrínsecos.

O alcance de bons níveis de satisfação no trabalho é influenciado tanto por fatores relacionados ao trabalho quanto ao profissional. Neste sentido, Marqueze e Moreno (2005) sintetizam dois componentes principais determinantes da avaliação desta variável por parte do trabalhador: o afetivo-emocional e cognitivo.

Verificou-se também que a renda familiar dos que trabalham na área escolar e não escolar simultaneamente é menor que a renda familiar dos que trabalham somente em ambientes não escolares. Uma hipótese a ser discutida é que pessoas com condição financeira familiar melhor tendem a ir para academia/clubes/condomínios, pois tem a segurança financeira da família e tem menor necessidade da estabilidade que o serviço público proporciona. Essa hipótese necessita de estudos futuros para comprovação.

\section{Considerações finais}

Destacam-se no presente estudo as seguintes conclusões: 1) a maioria dos egressos do DEF/UNIR está atuando em sua área de formação, e as escolas e academias de ginástica/musculação são os CA mais frequentes; 2) estatisticamente, não há diferenças entre os profissionais que atuam e não atuam na área de EDF tanto na renda quanto no escore global de satisfação profissional; 3) entre os graduados em EDF que não atuam na área os motivos mais frequentes para não atuação foram desvalorização profissional e salarial, falta de oportunidade e o fato de já ter concurso público 
Onde atuam, por que não atuam e o quão satisfeitos com o trabalho...

Gilson Junior Oliveira Lopes • Daniel Delani • Silvia Teixeira de Pinho • Tatiane Gomes Teixeira

em outra área; 4) a renda própria daqueles que trabalham no ambiente escolar e não escolar não tem diferença estatística, porém aqueles que atuam fora da escola apontaram renda superior em cerca de $R \$ 1.000,00$ em relação aos profissionais que atuam nas escolas; 5) tanto os profissionais que atuam na escola como no ambiente não escolar apresentam classificação geral de satisfação indiferente; e 6) os profissionais que atuam no ambiente não escolar apresentaram satisfação somente em um dos domínios (colegas) e apresentaram insatisfação em um deles, enquanto os profissionais que atuam em escolas apresentaram satisfação em três domínios (colegas, chefia e natureza do trabalho) e insatisfação em nenhum.

Este trabalho tende de fomentar novos estudos e discussões, abrangendo todo universo que envolve o profissional de EDF em prol do desenvolvimento e valorização da profissão perante a sociedade. Neste sentido, as IES têm grande importância. Sugere-se que elas criem planos de acompanhamentos dos egressos, visando abordar questões referentes ao local de atuação, satisfação no trabalho, perfil profissional, empregabilidade, pós-graduação, biblioteca virtual com trabalhos exclusivos da área, banco de currículo, divulgação de cursos, entre outros.

\title{
Referências
}

\begin{abstract}
AZEVEDO, A. J. D.; MEDEIROS, M. da P. M. de. Satisfação no trabaIho: um estudo de caso na Procuradoria-Geral de Justiça do Rio Grande do Norte. Revista Eletrônica Machado Sobrinho, Juiz de Fora, v. 1, 2012.
\end{abstract}

CONSELHO FEDERAL DE EDUCAÇÃO FÍSICA (CONFEF). Resolução CONFEF N $\mathbf{N}^{\circ}$ 46/2002. Disponível em: https://www.confef.org.br/ confef/resolucoes/82. Acesso em: 21 dez. 2018.

CORDEIRO, C. M. G. Satisfação no trabalho do professor de Educação Física em instituições de ensino fundamental e 
médio privadas em comparação com as academias. Porto Velho: UNIR, 2009.

ESPÍRITO-SANTO, G.; MOURÃO, L. A auto-representação da saúde dos professores de educação física de academias. Revista Brasileira de Ciências do Esporte, Campinas, v. 27, n. 3, p.39-55, maio 2006.

FOLLE, A.; BORGES, L. J.; COQUEIRO, R. S.; NASCIMENTO, J. V. Nível de (In) satisfação profissional de professores de Educação Física da educação infantil. Motriz, Rio Claro, v. 14. n. 2, p.124-134, abr./ jun. 2008.

GASPAR, R. A. Os campos de atuação do egresso do curso de Educação Física da UFSC após a fragmentação em licenciatura e bacharelado: diferenças e regularidades. 2013. $187 \mathrm{f}$. Dissertação (Mestrado em Educação) - Universidade Federal de Santa Catarina, Florianópolis, 2013.

IORA, J. A.; SOUZA, M. S.; PRIETTO, A. L. A divisão licenciatura/ bacharelado no curso de Educação Física: O olhar dos egressos. Movimento, Porto Alegre, v. 23, n. 2, p.461-474, 2017.

MARQUEZE, E. C.; MORENO, C. R C. Satisfação no trabalho - uma breve revisão. Revista Brasileira de Saúde Ocupacional, São Paulo, v. 30, n. 112, p.69-79, 2005.

MENDES, A. D.; AZEVÊDO, P. H. O trabalho e a saúde do educador físico em academias: uma contradição no cerne da profissão. Revista Brasileira de Educação Física e Esporte, São Paulo, v. 28, n. 4, p. 599-615, out./dez. 2014.

OLIVEIRA J. E. C. O campo de atuação do profissional de Educação Física e do Esporte. Lecturas Educación Física y Deportes, Buenos Aires, v. 161, p. 1-12, 2011.

PANDA, M. D. J.; SANTOS, M. K. Nível de satisfação com a formação e a trajetória de egressos de um curso de licenciatura em educação física da unicruz/rs. Cinergis, [s.I.], v. 14, n. 2, 2013. GOVERNO DE RONDÔNIA (RONDÔNIA). Portal da Transparência, Rendimentos dos Servidores Públicos, exer- 
Onde atuam, por que não atuam e o quão satisfeitos com o trabalho...

Gilson Junior Oliveira Lopes • Daniel Delani • Silvia Teixeira de Pinho • Tatiane Gomes Teixeira

cício 2017. Disponível em: http://transparencia.ro.gov.br. Acesso em: 25 set. 2017.

ROSA, P. Fatores intrínsecos e extrínsecos relacionados à satisfação/insatisfação com o trabalho: um estudo de caso dos servidores da Secretaria de Estado da Fazenda do Governo de Santa Catarina - Brasil. 2016. 97 f. Dissertação (Mestrado em Gestão de Empresas) - Universidade Lusófona de Humanidades e Tecnologias, Lisboa, 2016.

SIQUEIRA, M. M. M. Antecedentes de Comportamentos de Cidadania Organizacional: a análise de um modelo pós-cognitivo. 1995. 265 f. Tese (Doutorado em Psicologia) - Universidade de Brasília, Brasília, 1995.

\section{Aprovação de comitê de ética em pesquisa}

Pesquisa aprovada pelo Comitê de Ética da Universidade Federal de Rondônia . Título: Formação e Atuação profissional na área de Educação Física.

\section{Publisher}

Universidade Federal de Goiás. Faculdade de Educação Física e Dança. Publicação no Portal de Periódicos UFG. As ideias expressadas neste artigo são de responsabilidade de seus autores, não representando, necessariamente, a opinião dos editores ou da universidade. 